\title{
Improvement Of Confidence And Motivation Using Online Metacognition Tool
}

\author{
Quamrul H. Mazumder, University of Michigan-Flint, USA
} Mary Jo Finney, University of Michigan-Flint, USA

\begin{abstract}
The use of technology such as laptop computers in the classroom has long been recognized as destructive behavior since it diverts a student's attention from course topics. However, it is conceivable that every student will be using some form of technology in the near future. Determining the effects of interactive software on students' learning outcomes can have a profound effect on engineering education. The ultimate aim of this research is to transform students into active learners who are able to better comprehend, are less distracted, and can achieve higher academic performance. In this study, first year engineering students used online metacognition software while interactively participating in the classroom. Both qualitative and quantitative methods using the pre-and post-test experimental designs as well as a debriefing questionnaire were utilized. The academic achievement of students' through the integration of interactive technology was the output variable, while the input variables were divided into four categories: students' understanding of the concepts, confidence level, apprehension level, and motivation. In addition, this study also examined the amount of class participation to measure students' communication apprehension and its correlation to academic performance.

In order to improve students' learning outcomes using metacognitive strategies, it was discovered that the use of interactive technology followed by group discussions and class assignments greatly enhanced students' comprehension of scientific facts and their ability to explain them. In addition, the current study showed that engineering students' communication apprehension was also reduced resulting in improvement in confidence and motivation towards academic success.
\end{abstract}

Keywords: Metacognition; Communication Apprehension; Intrinsic Motivation

\section{INTRODUCTION}

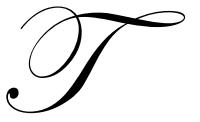

he recent increase of laptops and other similar devices in the classroom has virtually replaced manual note taking. Technology in the classroom has been demonstrated to enhance teacher and student technology literacy, student responsibility, and student independence. The quality of a student's work and the content of his/her presentations have improved as well (Fouts \& Stuen, 1997; Gardner, Morrison, Jarman, Reilly \& McNally, 1994). As laptops gain popularity in the classroom, so too is the use of multimedia and presentation software since it offers students and educators a unique way to introduce complex subject matters to the novice. Multimedia software using graphics, videos, and animations provides the ability to interact electronically with students with different learning styles (Ayersman, 1996; Provenso, Brett \& McCloskey, 1999). This constructivist approach encourages the learning of the material content through more sophisticated cognitive interactions (Siegle, Foster, 2001). Constructivism involves learning material based upon the experiences of those learning to construct much of what they understand (Schunk, 2000).

The use of interactive software such as LectureTools can sculpt students into active learners (Thorsen, 1998) by empowering them with the ability to direct their learning through the use of sophisticated cognitive strategies such as metacognition. There are two basic elements to metacognition: knowledge of cognition and 
regulation of cognition (Flavell, 1976). Knowledge of cognition refers to "what" individuals know about their own cognition. Furthermore, knowledge of cognition is composed of three types of awareness: (1) declarative: knowing what components dominate one's own performance; (2) procedural: knowing how to do things; and (3) conditional: knowing the why and when aspects of cognition (Brown 1987). Knowing when and what to rehearse is a strategy employed by successful students. The second basic element of metacognition involves regulation of cognition, which involves controlling a set of activities that facilitates and improves one's learning. Metacognitive regulation enhances achievement in several ways. First, students' display better handling of their attentional resources; second, students demonstrate greater execution of existing strategies; third, students display an enhanced understanding of comprehension breakdowns (Schraw, 1998). A number of studies have concluded that improvement of one's regulatory skills significantly improves one's learning. Moreover, it was reported that younger students are better able to acquire metacognitive skills if such skills are taught as part of classroom instruction (Cross 1988, Brown, 1989).

\section{LITERATURE REVIEW}

The use of multimedia based instruction in biology, engineering, anatomy, and physiology classrooms resulted in a higher level of understanding of the subject matter and improved exam scores. Ritt and Stewart (1996) observed that students who used technology in the classroom outperformed their counterparts by scoring, on average, 10 points higher on their exams. They also reported 9 out of 10 students who used different multimedia learning software improved their understanding of the course materials. Lunsford (1979) observed that basic writers function at a cognitive developmental level below what is required to achieve abstract thinking. Students who have not mastered the basic learning skills are unable to successfully apply the necessary principles required to succeed at the college level. This effects their motivation to learn, most likely converting it from intrinsic to extrinsic motivation (Logan et al., 2010). Intrinsic motivation is defined as the internal motivation within an individual such as curiosity, whereas extrinsic motivation is defined as the external motivating factors such as grades (Logan et al., 2010). Wittrock (1986) observed that in order to develop those schemata, students need to learn and consciously employ strategies or sequences of thought that encourage them to engage with different types of written text. Lepper (2005) discovered that intrinsic motivation was positively correlated to students' academic performance and that extrinsic motivation was negatively correlated to academic performance. Lau and Chan (2003) demonstrated that good and poor readers differ significantly in their levels of intrinsic reading motivation but not extrinsic motivation. As Logan (2010) observed, a student's motivation plays a greater role in his/her performance and the development of reading comprehension skills.

In Musical Excellence, Aaron Williamson (2004) discussed how every good musician needs to have the necessary skills to concentrate, set goals, set up flexible practice schedules, and most of all, have the ability to selfevaluate. These attributes are dependent upon the motivation of individual students, which has also been observed as an important factor in overall academic performance during this study.

\section{METACOGNITION}

Metacognition strategies are management techniques by which learners control their learning processes through planning, monitoring, and evaluating approaches (Rubin 1990). Planning includes choosing suitable strategies such as paying careful attention before starting a task. Monitoring includes one's understanding of comprehension and task accomplishment such as self-testing during learning. Evaluating refers to assessing the knowledge acquired and proficiencies of one's learning (Schraw, 1998). These strategies center on focusing, planning, and evaluating one's own progress as measured by academic performance (Flavell 1976). The difference between cognitive and metacognitive knowledge (Flavell 1979) is that the metacognitive approach focuses on how the knowledge is used by students. Metacognition refers to knowing what you know or thinking about thinking. Cognitive strategies assist an individual in attaining a certain goal, such as comprehending a text, while metacognitive strategies assure achievement of the goal by quizzing oneself to assess understanding for example (Livingston 1997). Cognitive approaches suggest that low self-perceived ability inhibits achievement and high selfperceived ability fosters and encourages higher levels of learning and attainment of goals. 


\section{COMMUNICATION APPREHENSION}

As students enter college, many of them refrain from asking questions to improve their level of understanding in the materials being presented in the classroom. Georgios Sideridis (2006) demonstrated in his study of 538 students that some students are overwrought with the "ought-self". He describes the "ought-self" as being "obliged to engage in an activity that is grounded on fear and is associated with a network of avoidancerelated behaviors." This explains the significant amounts of variability in task avoidance, performance avoidance, and fear of failure. Students demonstrating strong "ought-self" behavior were negatively associated with achievement and positively associated with indices of anxiety and depression. Students who are intrinsically motivated tend to employ more metacognitive strategies than students who are extrinsically motivated. Other studies have found that students who are extrinsically motivated through rewards eventually lose intrinsic interest (Grolnick \& Ryan, 1987). Some of these intrinsically motivated values "come from an individual's formation of a cognitive schema that is integrated into one's values which lead to fully self-determined behaviors" (Sideridis, 2006).

\section{RESEARCH GOAL}

The aim of this study was to engage students' metacognitive strategies in order to improve learning and academic performance. The study also examined the communication apprehension levels of students to determine if they inhibited class participation. It also attempted to understand if the causes of underachievement are due to communication apprehension, motivational deficits, or failure to use metacognitive strategies.

\section{DESIGN OF THE STUDY}

\section{Methodology}

This study used both qualitative and quantitative methods using the pre- and post-test experimental designs as well as a debriefing questionnaire. Academic achievement through the integration of interactive technology was the dependent variable. Students' understanding of the concepts, confidence level, apprehension level, and motivation to learn were the four independent variables used.

1. Students' understanding of engineering concepts and phenomenon, which was measured in two levelsstudents either grasp the material or they did not.

2. Students' confidence level (which was measured by the number of hours spent studying for exams and preparing for class), class participation (which was measured by the number of questions asked), and the grade they expected on an exam (which was examined before lecture using pre-test questionnaires and after lecture using post-lecture questionnaires).

Two other areas that were examined in this study involve:

1. Students' apprehension level - analyzed by converting confidence level scores and comparing them to exam scores to determine level of apprehension and possibly communication apprehension.

2. Students' motivation to learn engineering - examined by questions $1,3,5,7$.

Identical pre and post- test questionnaires were used to evaluate comprehension, confidence levels, and motivation to learn the materials presented in the classroom. The questionnaire (Appendix A) examined students' understanding of metacognition concepts as well as their confidence levels. The second part, the debriefing questionnaire (Appendix B) examined students' motivation to use technology in the classroom. There were nine Likert type questions, one multiple choice question, one yes/no question and one open ended question used to determine the students' level of intrinsic motivation:

a. Personal interest and enjoyment of the content (questions $1,2,12^{*}$ )

b. Motivation to use technology (questions 3, 4, 5, 6, 7*, 9*, 11*)

c. Ability to effectively communicate (question 8) 

analysis.

The questions marked with an asterisk were negative statements and have been recorded for statistical

Prior to taking their mid-term exam, participants were asked to complete a pre-test survey that was designed to measure their level of ability and confidence in the subject matter. Following the exam, the participants were asked to complete a post-test survey which was identical to the pre-test questionnaire and designed to assess the level of accuracy of their knowledge. The results of the pre-test were compared to mid-term exam scores. Later the mid-term exam scores were compared to the post-test survey to determine how accurately students recorded their assessment of understanding the subject matter.

As part of the study, both the pre and post-test questionnaires were administered before and after each lecture using interactive software. Also, this occurred before and after each quiz and exam.

\section{RESEARCH METHODS}

This research was conducted in two phases: 1. a pilot study to establish the research tools' reliability and validity, and 2. the main study to answer the research questions. Both phases used similar lecture materials presented by the same professor. The pilot study had 23 students registered for the class ( 21 males and 2 females); the main study consisted of 32 students (28 males and 4 females). The metacognition based software Lecture Tools (http://www.lecturetools,com) provided the interactive environment for the students. The interactive lecture was presented once a week for each topic taught in class. Each interactive session started with a pre-test and was followed by a post-test as shown in Figure 1. At the end of the class students met in groups of three or four to discuss the lecture materials and to answer the post-test

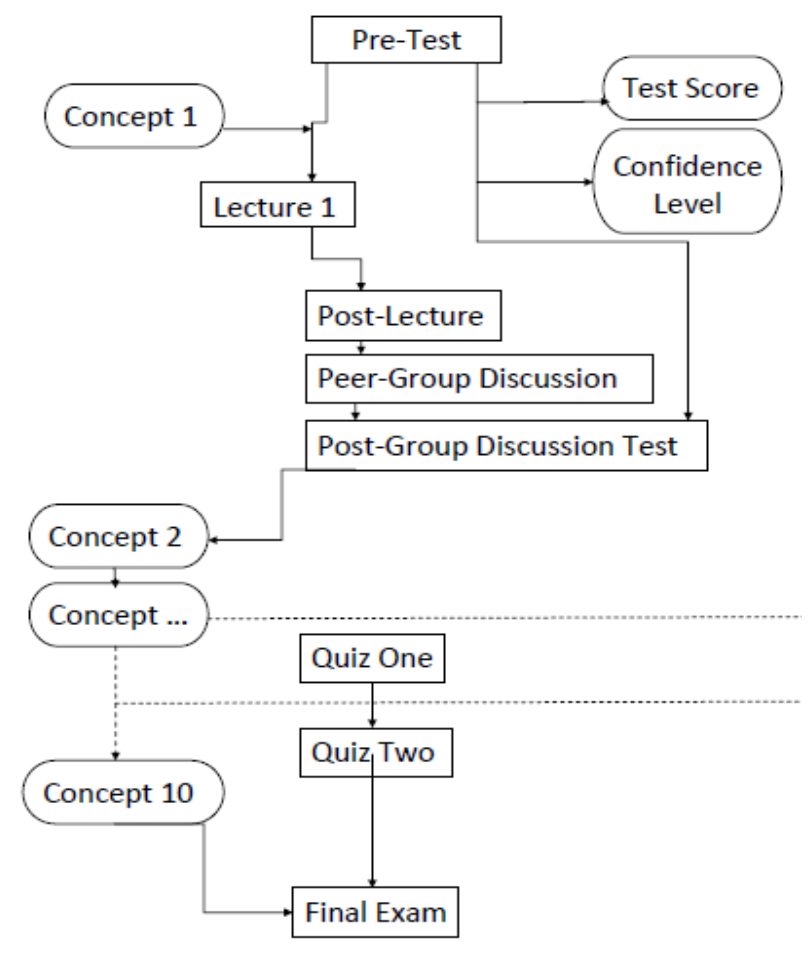

Figure 1: Overview Of Research Method 
Using the metacognition based software, students were able to view the lecture on their laptop and provide real-time feedback about their level of understanding of the topics presented. Based on the students' feedback, the professor reviewed topics as necessary in order to enhance the learning process. Students were also able to ask questions in an interactive mode while remaining totally anonymous. The results showed a significant increase in the number of students who asked questions using the online metacognition tool.

Table 1: Comparison Of Exam Scores, Hours Spent Studying, And Confidence Levels Of Students With And Without Technology

\begin{tabular}{|l|l|c|c|c|c|}
\hline & Technology vs. No Technology & $\mathbf{N}$ & Mean & Std. Deviation & Std. Error Mean \\
\hline \multirow{2}{*}{$\%$ Score on Exam } & No Technology & 23 & 78.622 & 12.8348 & 2.6762 \\
\cline { 2 - 6 } & Technology & 32 & 84.844 & 16.5458 & 2.9249 \\
\hline \multirow{2}{*}{ Hours studied } & No Technology & 17 & 2.88 & 1.317 & .319 \\
\cline { 2 - 6 } & Technology & 32 & 3.02 & 2.172 & .384 \\
\hline \multirow{2}{*}{ Expected score } & No Technology & 12 & 60.00 & 28.920 & 8.348 \\
\cline { 2 - 6 } & Technology & 32 & 33.94 & 6.618 & 1.170 \\
\hline
\end{tabular}

Table 1 shows that students who did not receive instruction through the use of technology scored lower than students receiving instructions through the use of technology. However, students who did not receive technology expected a higher grade than those who did receive technology. Although these students did not score higher on their exams, they had a higher level of confidence in their self- assessment.

\section{RESEARCH POPULATION}

The research population consisted of fifty-five students. Phase one consisted of first year engineering students signed up for EGR102 $(N=23)$ and phase two of the study also consisted of freshman engineering students signed up for the same class $(N=32)$. Two groups of freshman engineering students were studied over the course of two years. They alternately employed the use of laptop computers in the classroom with multimedia software to enhance their comprehension of engineering concepts taught at the University of Michigan-Flint. Each group used their laptop computers for the first half of the semester but switched to the traditional methods of note taking during the second half of the semester. The course grades of the two groups were compared at two weeks intervals during each semester and at the end of each semester.

\section{RESULTS}

To test the hypothesis that low perceived ability impedes performance, statistical analyses were performed based on intra-individual correlation coefficients between pre-test, exam and post-test performances of each participant. The analysis results indicated that students benefited from using interactive software and reviewing course material in groups after it was presented.

The following section is categorized into four subsections to answer each of the research questions. The first subsection describes students' understanding of engineering concepts by measuring the accuracy of their selfassessment of their level understanding of the subject matter in the post-test questionnaire. The second subsection measures the students' confidence levels of the subject before and after each lecture and exam. The third subsection examines students' communication apprehension by comparing class participation to final score in the class. The fourth subsection analyzes the students' intrinsic motivation to learn engineering as retrieved from the questionnaire.

\section{Students' Understanding Of Engineering Concepts And Phenomenon}

The statistical method Cronbach's Alpha was used to estimate the internal consistency of the five-items used to determine the confidence level of students. The results showed the value of alpha to be 0.644 , indicating a medium degree of internal consistency. The means of the individual items ranged from 1.54 to 3.04, with a mean on the total scale of $12.36(S D=3.76)$. Overall, the participants' responses on the scale indicated that they possess a mid-range level of confidence with regard to their understanding of the subject matter (Mazumder \& Ainsworth, 2010). 


\section{Students' Confidence Levels}

One of the hypotheses was that students might regulate their own learning by improving their ability to self-assess their understanding. A two-way ANOVA was also performed to evaluate whether the amount of time spent studying for exams and confidence levels had an impact on academic performance on exams. The analysis results revealed a significant main effect of hours spent preparing for an exam and the grade expected, $F(1,2)=$ $8.00, p<.05$. In other words, students who spent more time preparing expected to receive higher grades.

\section{Estimated Marginal Means of GradeExpected}

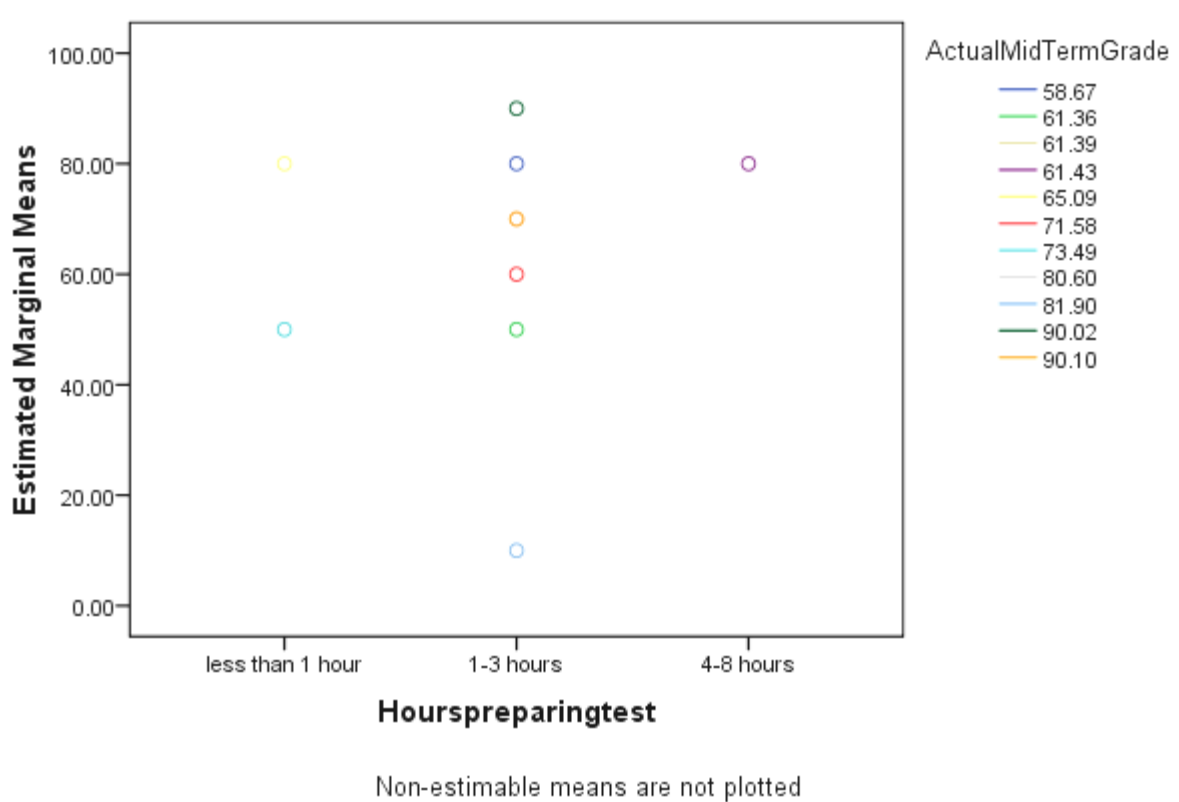

Figure 2: Means Of Grade Expected On Exam Vs. Hours Spent Studying For Exam

Table 2: Correlations Of Total Questions Asked To Final Exam Scores

\begin{tabular}{|c|c|c|c|c|}
\hline & & & Final Exam & Total Quest Asked \\
\hline \multirow[t]{6}{*}{ Spearman's rho } & \multirow[t]{3}{*}{ Final Exam } & Correlation Coefficient & 1.000 & $.437^{*}$ \\
\hline & & Sig. (2-tailed) & & .012 \\
\hline & & $\mathrm{N}$ & 32 & 32 \\
\hline & \multirow[t]{3}{*}{ Total Quest Asked } & Correlation Coefficient & $.437^{*}$ & 1.000 \\
\hline & & Sig. (2-tailed) & .012 & . \\
\hline & & $\mathrm{N}$ & 32 & 32 \\
\hline
\end{tabular}

*. Correlation is significant at the 0.05 level (2-tailed).

Due to non-normal distributions of grade and questions asked, non-parametric tests were conducted. The correlation between the frequency of total questions asked and the final exam score is presented in Table 2 . The frequency of questions asked in person and the frequency of questions asked online were also compared to exam grades. The results indicate a positive correlation between the number of questions asked by students and their final exam score. In other words, students who asked more questions also did better on the final exam. This is statistically significant as the correlation coefficient is $r(30)=+1.0, p<.05$. The coefficient of determination $\left(r^{2}\right)$ was calculated to determine the proportion of variance in one variable that is accounted for by another variable (Jackson, 2005). The coefficient of determination of $r^{2}=19.0 \%$ shows $19 \%$ of the variation in the final exam score is explained by the total number of questions asked in class, $p=.01$. 
Table 3: Relationship Between Number Of Questions Asked Online To Final Exam Scores

\begin{tabular}{|c|c|c|c|c|}
\hline & & & Final Exam Score & Questions Asked online \\
\hline \multirow[t]{6}{*}{ Spearman's rho } & \multirow[t]{3}{*}{ Final Exam Score } & Correlation Coefficient & 1.000 & $.516^{* *}$ \\
\hline & & Sig. (2-tailed) & & .002 \\
\hline & & $\mathrm{N}$ & 32 & 32 \\
\hline & \multirow[t]{3}{*}{ Questions Asked Online } & Correlation Coefficient & $.516^{* *}$ & 1.000 \\
\hline & & Sig. (2-tailed) & .002 & \\
\hline & & $\mathrm{N}$ & 32 & 32 \\
\hline
\end{tabular}

**. Correlation is significant at the 0.01 level (2-tailed).

The correlation between number of questions asked online to final exam score is presented in Table 3 to understand how the metacognition based Lecture Tools assisted students in participation and improvement of their academic performance. The total number of questions asked online are related to final exam scores by a +1.0 which suggests a strong positive correlation between the total number of questions asked online in relation to final exam scores.

A Spearman correlation coefficient was calculated for the relationship between the number of questions asked online and the final exam scores. This is statistically significant at $r(30)=.516, p<.01$, indicating a significant linear relationship between the two variables.

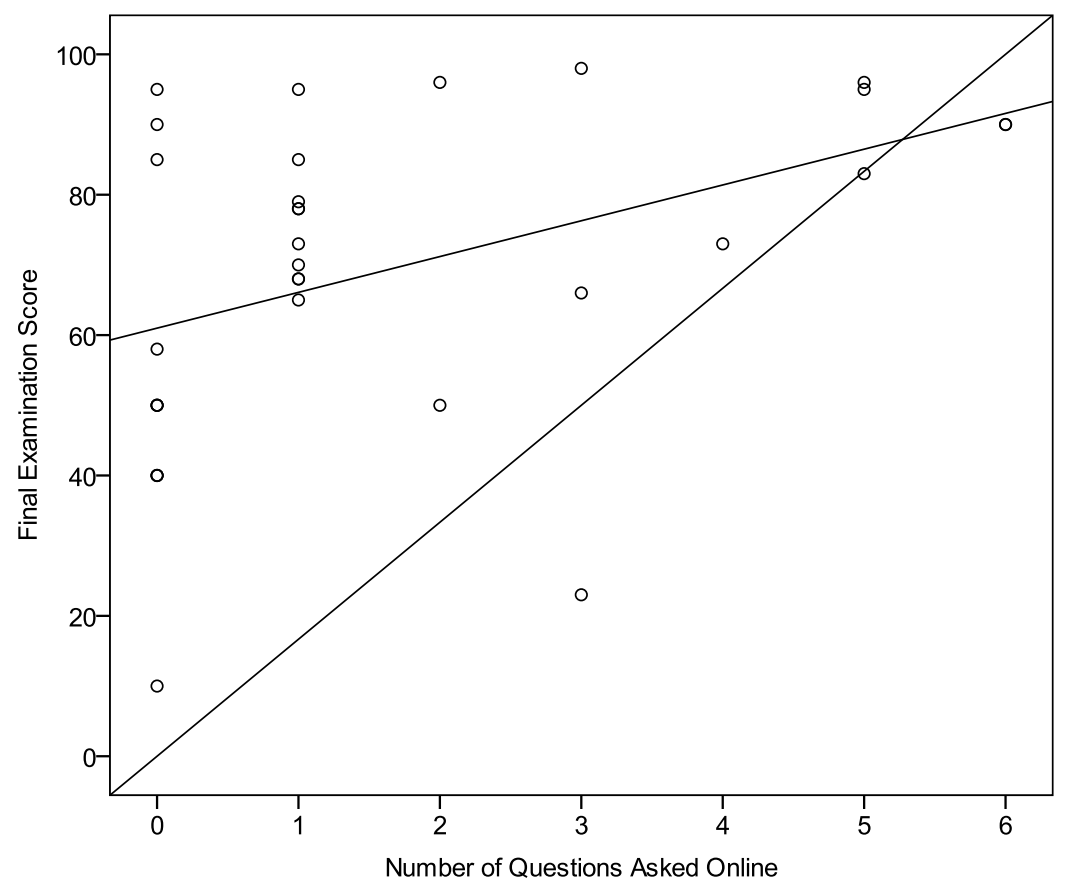

Figure 3: Correlation Between The Questions Asked Online And Final Exam Scores

The positive correlation of +1 indicates that as the number of questions online increases, final exam scores also increase. The coefficient of determination was calculated as $r^{2}=.266$, which indicates that $26.6 \%$ of the variation in final exam score, is explained by the total number of questions asked online (Jackson, 2005). Although, it did not appear that the numbers of questions asked online and the numbers of questions asked by hand are related. However, due to the fact that correlation coefficients only represent linear relationships, we are unable to conclude that there is no relationship between the two variables as Figure 4 shows that the variables have a curvilinear relationship. 


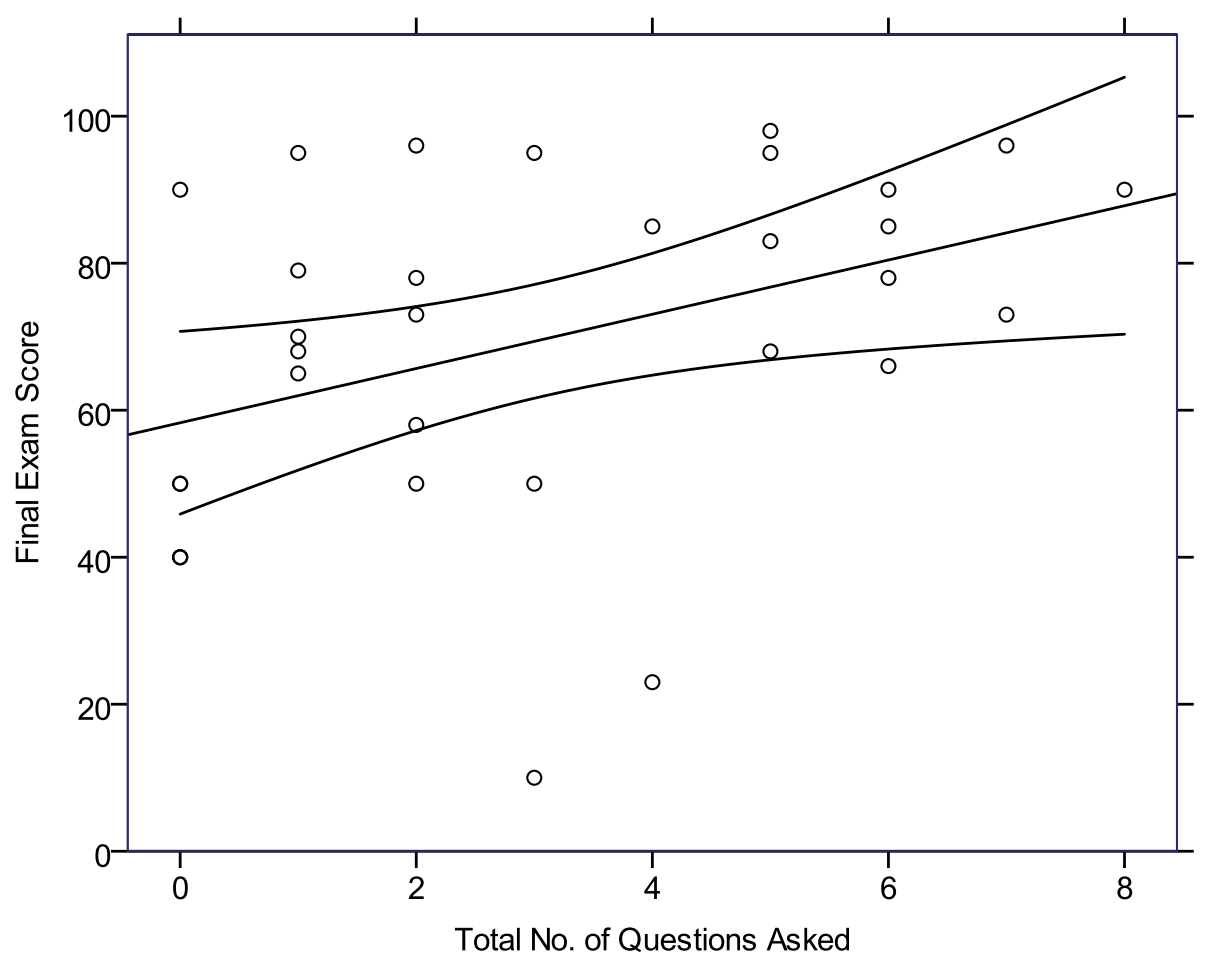

Figure 4: Comparison Of Total Number Of Questions Asked To Final Exam Scores

The concave line above the fit line (middle line) represents the questions asked online while the curved line below the fit line represents the total number of questions asked by hand. To understand the relationship additional tests should be conducted to determine the significance of this relationship.

\section{Students' Communication Apprehension}

This subsection of the study examined students' apprehension level. Apprehension level was analyzed by comparing students' confidence level scores with their exam scores. It was observed during the study that students who displayed communication apprehension may gradually withdraw from the learning process by not engaging in the classroom. Students who participated in class by asking questions and becoming involved with the interactive software seemed to retain a better overall comprehension, hence resulting in higher academic achievement than those who chose to not actively participate.

Table 4: Correlation Of Apprehension Level Vs. Final Class Score

\begin{tabular}{|c|c|c|c|c|}
\hline \multirow{2}{*}{ Spearman's rho } & & & Total Anxiety X? & Final actual score $\mathrm{X}$ ? \\
\hline & \multirow[t]{3}{*}{ Apprehension Level } & Correlation Coefficient & 1.000 & $-.681^{* *}$ \\
\hline & & Sig. (2-tailed) & 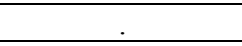 & .000 \\
\hline & & $\mathrm{N}$ & 32 & 32 \\
\hline & \multirow[t]{3}{*}{ Final actual score } & Correlation Coefficient & $-.681^{* *}$ & 1.000 \\
\hline & & Sig. (2-tailed) & .000 & . \\
\hline & & $\mathrm{N}$ & 32 & 33 \\
\hline
\end{tabular}

**. Correlation is significant at the 0.01 level (2-tailed). 
The relationship between students' apprehension level and final exam score is presented in Table 4. The analysis results showed $\mathrm{r}(30)=-.681, \mathrm{p}<.01$ indicating a significant linear relationship between the two variables. A strong negative correlation between apprehension level and final class grade explains why students with higher levels of apprehension had lower scores on the exam. Students who scored higher on the final exam had lower apprehension levels as shown in Figure 5.

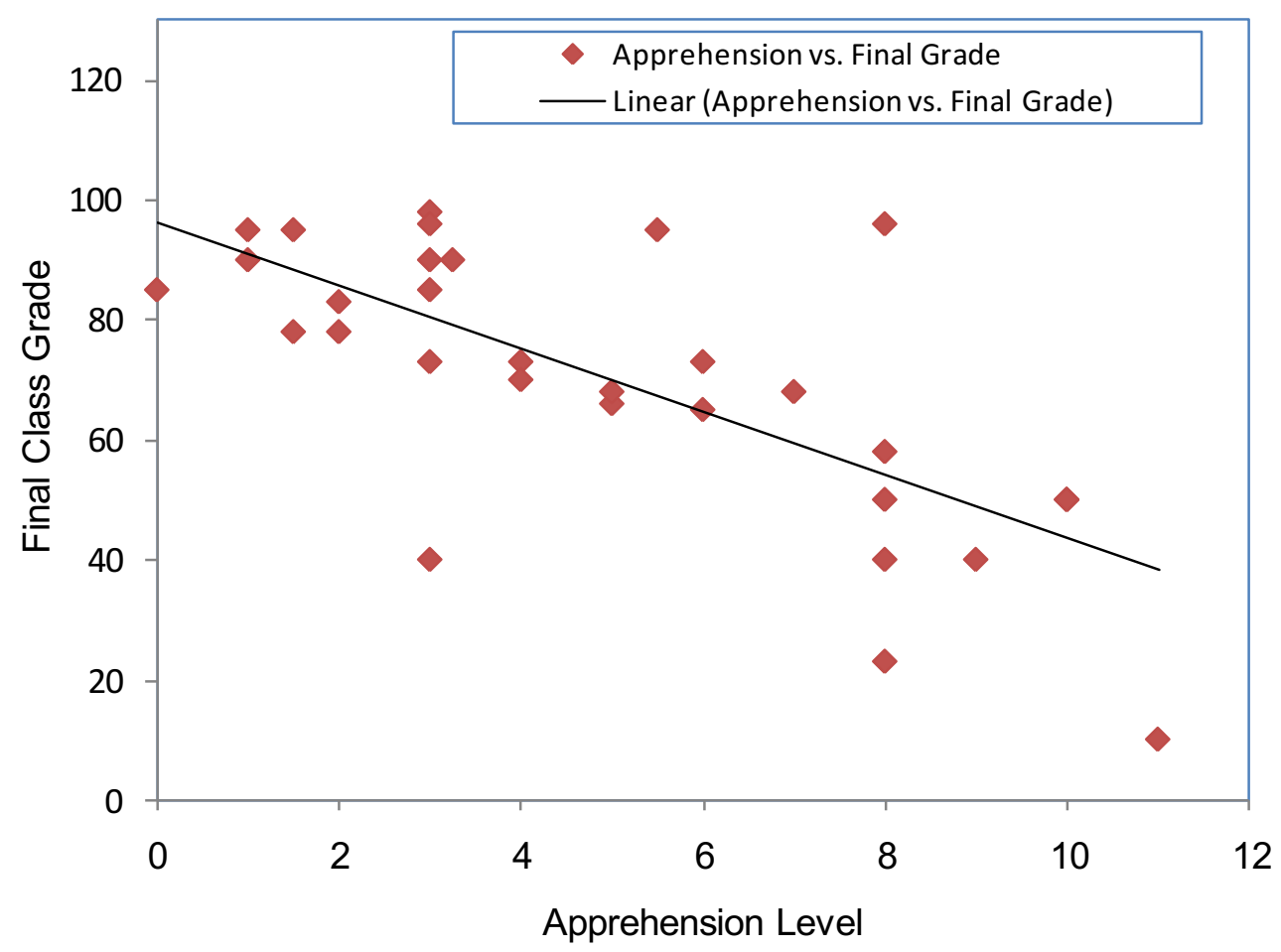

Figure 5: Correlation Of Students' Apprehension Levels And Final Grade

The large magnitude of Figure 5, shows a strong negative correlation between overall apprehension levels and final grade. The coefficient of determination, $r^{2}=.464$ indicates that $46.4 \%$ of the variation in final class score is explained by the students' apprehension level.

\section{Students' Intrinsic Motivation To Learn Engineering}

The response to the debriefing (Appendix B) reflects students' motivation to learn a new subject through intrinsic motivation as well as their willingness to experience the interactive software through the use of a laptop in the classroom.

Figure 6 shows several students had mixed responses to the questions. The students expecting a grade in the eighty percentile consistently answered five or above on all of the motivation questions. A score of five or above indicated that they are in strong agreement with the statement made in the questionnaire. 


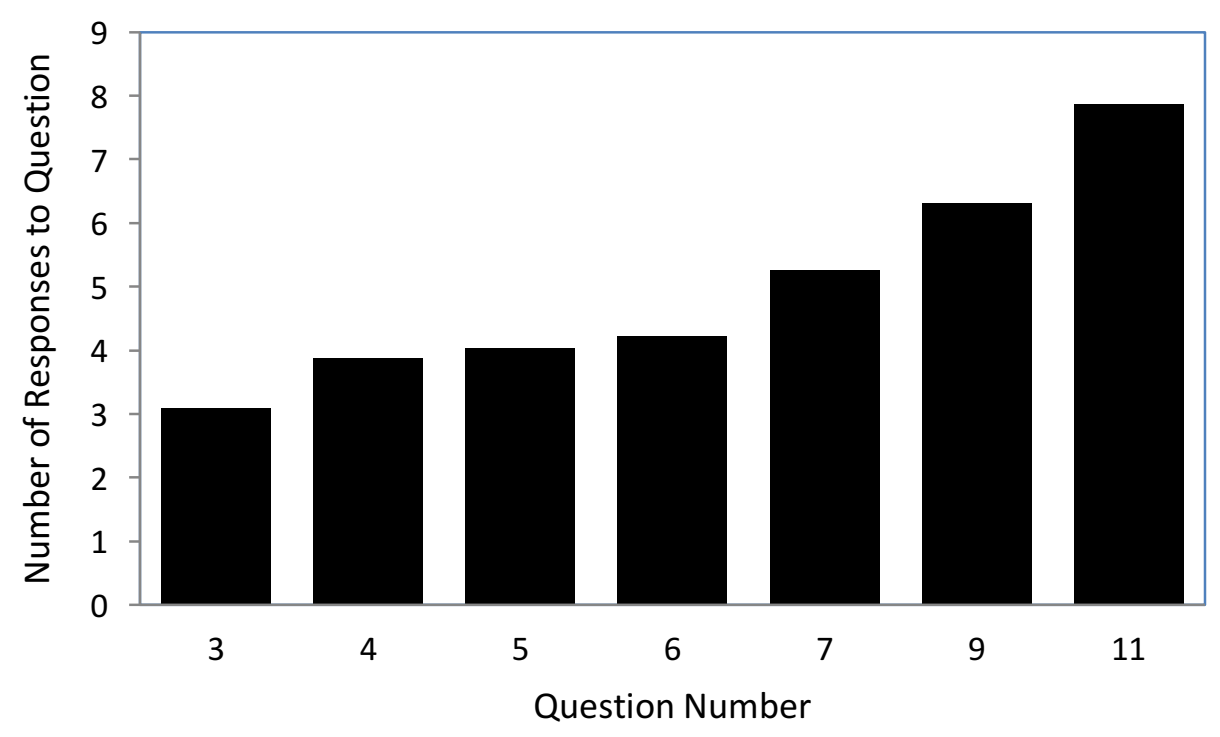

Figure 6: Students Motivation To Learn Through Intrinsic Motivation

\section{SUMMARY AND CONCLUSION}

The aim of this study was to engage students' metacognitive strategies to improve student learning. In this study, it was discovered that the use of interactive technology followed by group discussions and class assignments greatly enhanced students' comprehension of scientific facts and their ability to explain them. In addition, the study concluded that students who studied engineering through the use of interactive software greatly reduced their communication apprehension. This resulted in a building of confidence and development of greater motivation to learn the subject in relation to self-motivation, which is important to the student's future career goals.

Although it is challenging to assess whether the positive results are due to the use of laptops and interactive software in the classroom, it is obvious that the interaction positively contributed to the students paying more attention. The increased interactions improved their level of understanding of the subject matter, which resulted in higher exam scores. On the other hand, it is possible that clarification and further understanding of any questions could have resulted from the group discussion and not necessarily from the use of technology.

Even though it is well-known that top performing students already employ these strategies, the use of technology to trigger higher level of cognitive thinking may not be useful for that task if most of the students are already in the habit of planning, monitoring, and evaluating their learning. However, it may be useful for future studies to determine if a student's motivation may conceivably play a greater role in their performance even if they have lower abilities. Since few studies have been conducted in this area, this would be an excellent topic to conduct future studies. In addition, more studies need to be conducted in the area of communication apprehension and developing methods of teaching students how to engage and apply a higher level of cognitive thinking to their education.

\section{ACKNOWLEDGEMENTS}

The author would like to acknowledge financial support provided by National Science Foundation grant no: NSF 0837139 towards this study. Thanks to Anita Ainsworth and UM-Flint office of research for support with the statistical analysis. Professor Perry Samson of University of Michigan-Ann Arbor provided the LectureTool software used in this study. 


\section{AUTHOR INFORMATION}

Dr. Quamrul Mazumder is an associate professor of Mechanical Engineering at University of Michigan-Flint. His research areas include active learning, motivation, Metacognition based learning, quality improvement in higher education, computational Fluid dynamics, etc. As a consultant and keynote speaker, he is actively involved in assessment and quality Improvement at international level. E-mail: qmazumde@,umflint.edu.

Mary Jo Finney is an associate professor of education at the University of Michigan - Flint. She has an M.A.T. and Ph.D. in Reading and Language Arts and her research centers on print and video as media for learning, reading comprehension, writing, and cognitive misconceptions in science. Previously serving as dean and director of the UM-Flint Thompson Center for Learning and Teaching, Dr. Finney is now chair of the Education Department and directs a clinically-based urban teacher preparation program.

\section{REFERENCES}

1. Ayersman, D.J., (1996). Reviewing the research on hypermedia-based learning, Journal of Research on Computing in Education, 28(4), 500-526.

2. Brown, A.L., \& Palincsar, A.S. (1989) Guided, cooperative learning and individual knowledge acquisition. In L.B. Resnick, ed., Knowing and Learning: Essays in Honor of Robert Glaser, Hillsdale, NJ: Erlbum.

3. Caine, R. N., Caine, G. (1995). Reinventing schools through brain-based learning. Educational Leadership, 52, 43-47.

4. Cross, D.R. \& Paris, S.G., (1988). Developmental and instructional analyses of children's metacognition and reading comprehension. Journal of Educational Psychology 80, 131-142.

5. Flavell, J.H., (1976). Metacognitive aspects of problem solving. The Nature of Intelligence, Hillside, NJ: Lawrence Erlbaum Associates.

6. Flavell, J.H., (1979). Metacognition and cognitive monitoring: a new area of cognitive-developmental inquiry. American Psychologist, 34, 906-911.

7. Fogarty, R., McTighe, J., (1993). Educating teachers for higher order thinking: The three-story intellect. Theory into Practice, 32(3), 161-169.

8. Fouts, J. \& Stuen, C., (1997). Copernicus Project: Learning with laptops: Year 1 evaluation report. (ERIC No. ED 416 847).

9. Gardner, J., Morrison, H., Jarman, R., Reilly, C., \& McNally, H., (1994). Learning with portable computers. Computer \& Education, 22, 161-171.

10. Grolnick, W.S., \& Ryan, R. M., (1987). Autonomy in children's learning: An experimental and individual difference investigation. Journal of Personality and Social Psychology, 52, 890-898.

11. Jackson, S.L., (2005). Statistics, plain and simple. Thomson Wadsworth: Belmont, CA

12. Lau, K., \& Chan, D. W. (2003). Reading strategy use and motivation among Chinese good and poor readers in Hong Kong. Journal of Research in Reading, 26(2), 177-190.

13. Lepper, M. R., Henderlong Corpus, J., \& Iyengar, S. S. (2005). Intrinsic and extrinsic motivational orientations in the classroom: Age differences and academic correlates. Journal of Educational Psychology, 97(2), 184-196. http://lecturetools.com

14. Livingston, J.A., (1997). Metacognition: an overview. Retrieved August 27, 2010, from http://gse.buffalo.edu/fas/shuell/cep564/metacog.htm

15. Logan, S., Medford E. \& Hughes, N., (2010). The importance of intrinsic motivation for high and low ability readers' reading comprehension performance. Learning and Individual Differences 21, 124-128.

16. Lunsford, A.A., (1979). Helping students "get it together" with the synthesis journal. Retrieved August 04 2010, from http://www.umkc.edu/cad/nade/nadedocs/96conpap/pmcpap96.htm

17. Materna, L. E. (2000). Impact of concept-mapping upon meaningful learning and metacognition among foundation-level associate-degree nursing students. Retrieved July 8 2010, from http://proquest.umi.com/pqdweb?did-728371591\&

18. Mazumder, Q., Ainsworth, A. (2010). Use of metacognition strategy to improve student learning. Journal of Engineering Educators, Annual Conference Journal, June 2010.

19. Nuan, D. (1999). Second Language Teaching and Learning. Heinle \& Heinle. 
20. Oxford, R. (1990). Language Learning Strategies: What Every Teacher Should Know. Boston: Newbury House.

21. Ozden, M., Gultekin, M., (2008). The effects of brain-based learning on academic achievement and retention of knowledge in science course. Electronic Journal of Science Education (Southwestern University) 12(1), Retrieved from Http://ejse.southwestern.edu

22. Pool, C. R. (1997). Maximizing learning: a conversation with Renate Nummela Caine. Education Leadership, 54, 11-15.

23. Provenso, E. F. Jr., Brett, A., \& McCloskey, G. N., (1999). Computers, curriculum and culture change: An introduction for teachers, Mahwah, NJ: Lawrence Erlbaum Associates.

24. Redding, R. E. (1990). Metacognitive instruction: Trainers teaching thinking skills, Performance Improvement Quarterly, 3(1), 27-41.

25. Ritt, L., \& Stewart, B., (1996). Applying technology in the classroom, innovative strategies for teaching anatomy and physiology. Tech Trends, $41,1$.

26. Rowe, H., (1988). Metacognitive skills: Promises and problems, Australian Journal of Reading, 11(4), 227-237.

27. Rubin, D. L., (1990). Orality, oral-based, culture and the academic writing of ESL learners. Applied Linguistics, 1(1), 56-76.

28. Schraw, G., (1998). Promoting general metacognitive awareness. Instructional Science 26, 113-125.

29. Schunk, C. H., (2000). Learning theories: An educational perspective, Upper Saddle River, NJ: Merrill.

30. Sideridis, G.D., (2006). Achievement goal orientations, "oughts," and self-regulation in students with and without learning disabilities. Learning Disability Quarterly, 29 (1), 3-18.

31. Siegle, D., Foster, T., (2001). Laptop computers and multimedia and presentation software: their effects on student achievement in anatomy and physiology. Journal of Research on Technology in Education, 34(1), 29-37.

32. Stevens, J \& Goldberg, D. (2001). For the learners' sake: brain-based instruction for the $21^{\text {st }}$ century. Arizona: Zephyr Press.

33. Thorsen, C., (1998). Technology-based models for classroom teachers: Volume III. Teaching presentation software: Thinking in 3-D. Boise, ID: Boise State Educational Technology Program.

34. Williamson, A., (2004). Musical excellence: strategies and techniques to enhance performance Oxford: Oxford University Press.

35. Wittrock, M.C. (Ed.) (1986), Handbook of research on teaching, $3^{\text {rd }}$ d. New York: MacMillan. 


\section{APPENDIX A: Example Questions From The Metacognition Pretest}

- Which of the following is not part of metacognition?
a) Thinking about thinking
b) Examining your brains processing
c) Becoming a more strategic thinker
d) Rote memorization

- There are 3 stages of metacognition, which of the following is not one of these stages?
a) Planning
b) Monitoring
c) Evaluating
d) Learning

- The self-regulation process is

a) When you are not aware of your strengths and weaknesses

b) Students assessing their own abilities

c) Not helpful in informing you what you need to spend more or less time on

- Metacognition
a) Stresses active participation in problem solving
b) Increases knowledge about learning and problem solving
c) Increases capability of students to assess their own level of understanding
d) All of the above

\section{APPENDIX B: Lecture Tools: Debriefing}

1.) Which of these resources did you utilize outside of class throughout the semester? (check all that apply)
a.) Podcasts
b.) Online text books
c.) Other online resources
d.) Other hardcopy textbooks
e.) Lecture Tools slides from class, unaltered
f.) Lecture Tools slides from class, with additional notes
g.) Your hand-written /typed noted from class
h.) The hand-written/typed notes from class of classmates
i.) Studying one-on-one with the same classmate
j.) Studying one-on-one with multiple classmates
k.) Studying with more than one classmate as a small group
1.) Speaking with students who had previously taken the course
$\mathrm{m}$.) Office hours or scheduled meetings with the instructor or teaching assistants
n.) Other, please specify

2.) On average, how much time each week did you spend studying for this course outside of class?
a.) Less than 1 hour
b.) 1-2 hours
c.) 3-5 hours
d.) 6-8 hours
e.) 9 or more hours

3.) How often did you use a laptop in this class
a.) Every lecture
b.) Most lectures
c.) A few lectures
d.) Never 


\begin{tabular}{|ll|l|l|l|}
\hline STATEMENT & Strongly Agree & Somewhat Agree & Somewhat Disagree & Strongly Disagree \\
\hline 4.$)$ & Using a laptop increased my attentiveness in this class relative to other classes \\
5.) & Using a laptop increased my engagement in this class relative to other classes \\
6.) & My learning has been positively affected because of using a laptop in this class \\
7.) & $\begin{array}{l}\text { I spend more time on tasks unrelated to class/lecture than in other classes because of using a laptop in this } \\
\text { class }\end{array}$ \\
\hline
\end{tabular}

8.) I have asked at least one question, via Lecture Tools, during class this semester. Yes

No

9.) How distracted were you by other students' laptops?
a.) Not distracted
b.) Somewhat distracted
c.) Distracted
d.) Very distracted

10.) What else, if anything distracted you during class?

11.) On a scale of $1-5$, where 1 is very low and 5 is very high, to what degree was any lack of attentiveness in this class due to technical difficulties with your laptop?
a.) 1- Very low impact on attentiveness
b.) 2-Low impact on attentiveness
c.) 3- Medium impact on attentiveness
d.) 4-High impact on attentiveness
e.) 5-Very high impact on attentiveness

12.) On a scale of $1-5$, where 1 is very low and 5 is very high, to what degree was any lack of attentiveness in this class due to technical difficulties with the instructors' presentation?
a.) 1-Very low impact on attentiveness
b.) 2-Low impact on attentiveness
c.) 3-Medium impact on attentiveness
d.) 4-High impact on attentiveness
e.) 5-Very high impact on attentiveness 